\title{
Effect of Post-weld Heat Treatment on the Microstructure and Corrosion Resistance of Deposited Metal of a High- Chromium Nickel-Based Alloy
}

\author{
Xin-Jie Di ${ }^{1} \cdot$ Xiao-Qian Liu ${ }^{1} \cdot$ Cui-Xin Chen ${ }^{2} \cdot$ Bao-Sen Wang $^{3} \cdot$ Xiao-Jiang Guo ${ }^{4}$
}

Received: 6 June 2016/Revised: 26 August 2016/Published online: 27 October 2016

(C) The Chinese Society for Metals and Springer-Verlag Berlin Heidelberg 2016

\begin{abstract}
The evolution of $\mathrm{Cr}_{23} \mathrm{C}_{6}$ carbides in the deposited metal (DM) of a high-chromium nickel-based alloy was investigated after the post-weld heat treatment (PWHT) at $650,750,850$, and $950{ }^{\circ} \mathrm{C}$, respectively. With the increase in temperature, the morphology of the $\mathrm{Cr}_{23} \mathrm{C}_{6}$ carbides at the grain boundaries was transformed from the continuous lamellarlike to the semi-continuous rod-like and then to the discontinuous granular. Besides, the needle-like $\mathrm{Cr}_{23} \mathrm{C}_{6}$ carbides precipitated from $\gamma$ matrix after PWHT at $850{ }^{\circ} \mathrm{C}$. The coarsening kinetics of the needle-like $\mathrm{Cr}_{23} \mathrm{C}_{6}$ carbides obeyed the Lifshitz-Slyozov-Wagner law with the growth speed of $4.93 \mu \mathrm{m}^{3} / \mathrm{h}$ in length and $5.56 \times 10^{-3} \mu \mathrm{m}^{3} / \mathrm{h}$ in width. Moreover, the ratio of the carbide length to width increased rapidly at first and then flattened as the holding time increased to $850{ }^{\circ} \mathrm{C}$. The results of electrochemical corrosion experiment indicated that the needled-like $\mathrm{Cr}_{23} \mathrm{C}_{6}$ carbides impaired the corrosion resistance of DM due to the formation of chromium depletion around the carbides.
\end{abstract}

KEY WORDS: Post-weld heat treatment; Carbide precipitation; Morphology evolution; Electrochemical behavior

\section{Introduction}

$\mathrm{Ni}-\mathrm{Cr}-\mathrm{Fe}$ solid-solution-strengthened Ni-based alloys have wide applications prospect in nuclear power industry [1-3]. Before Filler metal 52 was developed, Filler metal 82 and 182 were the widely used consumables for nuclear

Available online at http://link.springer.com/journal/40195

Xin-Jie Di

dixinjie@tju.edu.cn

1 School of Materials Science and Engineering, Tianjin University, Tianjin 300072, China

2 School of Materials Science and Engineering, Hebei University of Technology, Tianjin 300130, China

3 Baosteel Research Institute, Baoshan Iron \&Steel Co., Ltd., Shanghai 200431, China

4 National Engineering Laboratory of Transportation Safety of Oil \& Gas Pipeline, Langfang 065000, China power fabrication and repair [4]. However, the application of Filler metal 82 and 182 in nuclear power industry showed that they were susceptible to primary water stress corrosion cracking (SCC) after several years [1]. In order to improve SCC resistance, the filler metals with high chromium, such as Filler metal 52, have been developed $[2,4,5]$. Unfortunately, based on practical production data and experiments results, these high-chromium nickel-based alloys were susceptible to hot cracking during welding $[6,7]$. The precipitates in the alloys, especially the carbides containing abundant alloying elements, had a complex effect on crack resistance depending on the precipitates characteristics and application environment [8-10]. Therefore, it was necessary to investigate the evolution of carbides in the high-chromium nickel-based alloy.

$M \mathrm{C}$ and $M_{23} \mathrm{C}_{6}$ were the common carbide types in nickelbased alloys during welding or the subsequent post-weld heat treatment (PWHT). The $M C$-type carbide ( $M$ denoted $\mathrm{Nb}$ or Ti) exhibiting a face-centered cubic crystal structure typically formed at the end of solidification by eutectic-type 
reactions with $\gamma$ matrix. The $M C$ carbide could be replaced by $M_{23} \mathrm{C}_{6}$ carbide featuring a complex cubic crystal structure in some superior superalloys with much higher operating temperatures and longer service lifetimes [11]. The $M_{23} \mathrm{C}_{6}$ carbide phase precipitated during aging heat treatment or in service in the temperature ranging from 650 to $1080{ }^{\circ} \mathrm{C}$ [12]. In most cases, the $M$ in $M_{23} \mathrm{C}_{6}$ was mainly on behalf of $\mathrm{Cr}$, and sometimes part of chromium atoms in $M_{23} \mathrm{C}_{6}$ would be replaced by molybdenum atoms. The formation of $M_{23} \mathrm{C}_{6}$ carbides would consume a large number of $\mathrm{Cr}$ and $\mathrm{Mo}$ atoms. Consequently, the corrosion resistance surrounding $M_{23} \mathrm{C}_{6}$ carbides would decrease owing to the depletion of $\mathrm{Mo}$ and $\mathrm{Cr}$ at that local region $[13,14]$.

According to the investigation of Angeliu and Was [15], $M_{23} \mathrm{C}_{6}$ carbide formed on the grain boundaries in alloy 690 with the morphologies of continuous, semi-continuous, or discontinuous. The discontinuous $M_{23} \mathrm{C}_{6}$ carbides in long strips stretched into the grains. The $M_{23} \mathrm{C}_{6}$ carbide also showed a needle-like morphology in nickel-based alloy 690 under the certain heat-treated condition [16]. Wang et al. [17] reported that nano-scaled $M_{23} \mathrm{C}_{6}$ carbide precipitated during high-temperature creep and distributed in the $\gamma$ matrix channels at intragranular regions.

It is known that the morphology and distribution of carbides had a crucial effect on the property of nickelbased alloys $[15,18]$, but the evolution mechanism of carbides in high-Cr nickel-based alloys is still not clear. This study investigated the $\mathrm{Cr}_{23} \mathrm{C}_{6}$ carbide evolution in the deposited metal (DM) of a high-Cr nickel-based alloy at different PWHT temperatures. And the evolution mechanism was expounded in detail. The effect of $\mathrm{Cr}_{23} \mathrm{C}_{6}$ carbides on the corrosion resistance of the alloy was revealed by electrochemical experiment and scanning electron microscopy (SEM).

\section{Materials and Methods}

The DM was prepared by GTA (gas tungsten arc) overlay welding layer with the high-chromium nickel-based alloy filler wire on the clean surface of Q235 steel plate, using a current of $115 \mathrm{~A} \mathrm{DC}$ and a voltage of $13.5 \mathrm{~V}$. The interpass temperature was controlled at $100{ }^{\circ} \mathrm{C}$ or less, and a welding speed of $25 \mathrm{~mm} / \mathrm{min}$ was maintained. The aswelded DM was peeled off from the Q235 steel and divided into eight samples that were transversely oriented in the welding direction. One of the samples (I) was selected as the as-welded sample. Four samples (II, III, IV, and V) were heated to $650,750,850$, and $950{ }^{\circ} \mathrm{C}$, respectively, and then hold for $4 \mathrm{~h}$. The other three samples (VI, VII, and VIII) were heated at $850{ }^{\circ} \mathrm{C}$ for 2,6 , and $8 \mathrm{~h}$, respectively. And the samples (II-VIII) undergoing the PWHT were cooled in a furnace. All samples were polished using standard metallographic techniques and then etched with mixed acid (hydrochloric acid/nitric acid/acetic acid $=1: 1: 1)$. The microstructure was examined and analyzed by optical microscope (OM, OLYMPUS GX51), scanning electron microscopy (SEM, JEOL JSM-6360LV), and transmission electron microscopy (TEM, PHILIPS CM200). SEM and TEM were equipped with an ultra-thin window Oxford energy-dispersive spectrometer (EDS). With the aid of EDS in SEM, the chemical composition of the DM in this study was obtained (wt $\%)$ : $30.32 \mathrm{Cr}$, $3.93 \mathrm{Mo}, 2.81 \mathrm{Nb}, 0.25 \mathrm{Al}, 0.4 \mathrm{Ti}, 0.05 \mathrm{Cu}, 8.06 \mathrm{Fe}, 0.31 \mathrm{Si}$, $0.21 \mathrm{Mn}, 0.02 \mathrm{C}$, and margin Ni. Using TEM, selected-area electron diffraction (SAED) analysis of the precipitates, which were prepared from the DM, was performed. Using a voltage of $75 \mathrm{~V}$, the thin foils were produced by twinjet polishing with $3 \%$ perchloric acid and $97 \%$ ethanol at temperatures that ranged from -25 to $-29^{\circ} \mathrm{C}$.

All of the electrochemical experiments were performed with a standard three-electrode cell. The DM, platinum sheet with a $10-\mathrm{cm}^{2}$ surface areas, and saturated calomel electrode (SCE) were used as working, counter, and reference electrodes, respectively. The electrolyte consists of $1.0 \mathrm{wt} \% \mathrm{H}_{2} \mathrm{SO}_{4}$ and $40 \mathrm{wt} \% \mathrm{CH}_{3} \mathrm{COOH}$. The test temperature was $(25 \pm 1){ }^{\circ} \mathrm{C}$. Working electrodes were immersed in solution. Experiments were repeated at least three times. Electrochemical impedance spectroscopy (EIS) and potentiodynamic polarization curve were measured by Autolab electrochemical analyzer device. The EIS measurements were taken in a frequency range from $100 \mathrm{kHz}$ to $0.01 \mathrm{~Hz}$ by applying $0.01 \mathrm{~V}$ amplitude to the system. After that, the potentiodynamic polarization curves were measured at $0.01 \mathrm{~V} / \mathrm{s}$ scan rate.

\section{Results and Analysis}

\subsection{Microstructural Evolution in DM}

Figure 1 shows the morphology of precipitated phase in the as-welded DM. According to our previous study [19], the white blocky particle was $\mathrm{TiC}$, and the island-like constituent was $\gamma /$ Laves eutectic structure.

Figure 2 shows the SEM and TEM analysis results of the precipitates at the grain boundaries in the DM after PWHT at $650{ }^{\circ} \mathrm{C}$. Figure 2a shows that there were continuously lamellar-like phases precipitated at some grain boundaries. However, the TEM observation shows that the lamellar-like precipitate was composed of many particles that compactly arranged in a row and grew along a certain orientation, as shown in Fig. 2b. The EDS spectrum (Fig. 2c) and SAED pattern (Fig. 2b) of the phase indicated that the lamellar-like phase was the $\mathrm{Cr}_{23} \mathrm{C}_{6}$ carbide, in which some $\mathrm{Cr}$ atoms were replaced by Mo atoms. The 


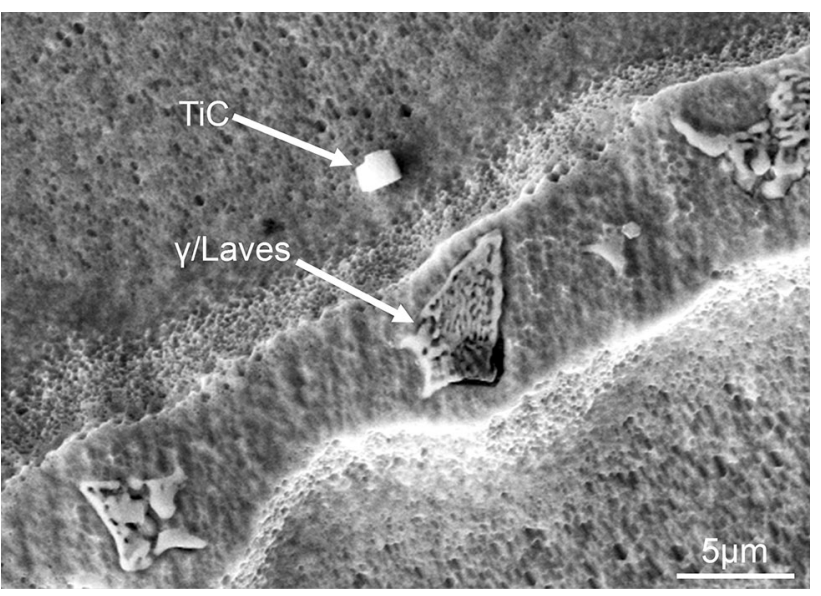

Fig. 1 SEM image of $\gamma /$ Laves eutectic structure and $\mathrm{TiC}$ in the welded DM

lamellar-like $\mathrm{Cr}_{23} \mathrm{C}_{6}$ carbide had a face-centered cubic crystal structure with a lattice parameter of $1.065 \mathrm{~nm}$. Moreover, the carbide was coherent with the $\gamma$ matrix following the orientation relationship of $(2 \overline{2} 4)_{\mathrm{Cr}_{23} \mathrm{C}_{6}} / /(\overline{1} \overline{1} \overline{1})_{\gamma}$.

When the PWHT temperature increased to $750{ }^{\circ} \mathrm{C}$, Fig. 3 shows that the morphology of $\mathrm{Cr}_{23} \mathrm{C}_{6}$ carbides at the grain boundaries presented as the semi-continuous rod-like shape. The $\mathrm{Cr}_{23} \mathrm{C}_{6}$ carbides became thicker than that at $650{ }^{\circ} \mathrm{C}$

The SEM and TEM analysis of the precipitates in the DM after PWHT at $850{ }^{\circ} \mathrm{C}$ is shown in Fig. 4. When the temperature increased to $850{ }^{\circ} \mathrm{C}$, Fig. $4 \mathrm{a}$ and b shows that the $\mathrm{Cr}_{23} \mathrm{C}_{6}$ carbides at grain boundaries were granular. And some granular $\mathrm{Cr}_{23} \mathrm{C}_{6}$ carbides precipitated in the grain interior nearby the grain boundaries with the average size of $0.5 \mu \mathrm{m}$. Besides, a large number of needle-like phases precipitated from the $\gamma$ matrix of DM and segmented the $\gamma$ matrix into many fragments. The TEM analysis revealed that the needle-like phase had a face-centered cubic crystal structure (Fig. 4c). And from EDS results, it can be obtained that the phase mainly contained $78.17 \mathrm{wt} \% \mathrm{Cr}$, $10.07 \mathrm{wt} \% \mathrm{Ni}$, and $6.49 \mathrm{wt} \%$ Mo. Hence, it can be

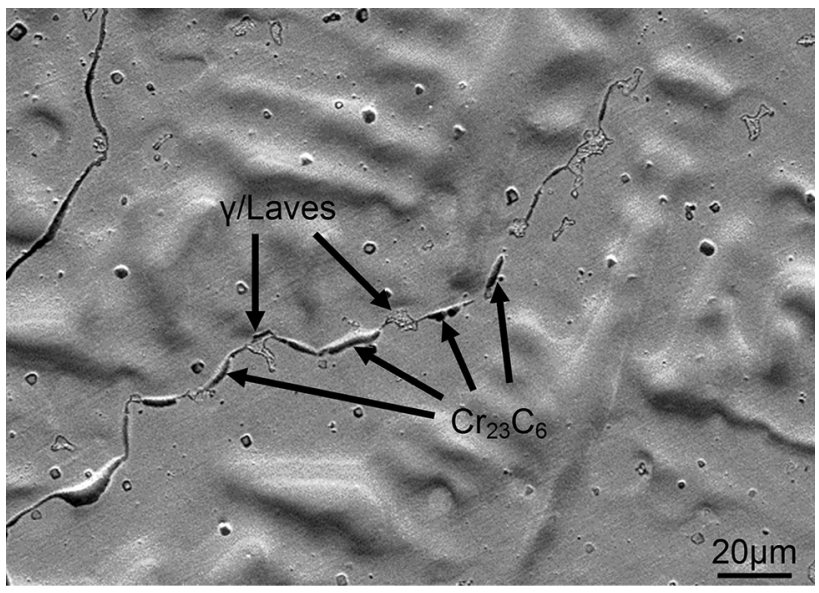

Fig. 3 SEM image of the $\mathrm{Cr}_{23} \mathrm{C}_{6}$ carbide and $\gamma /$ Laves eutectic structure at the grain boundary

concluded that the needle-like phase was $\mathrm{Cr}_{23} \mathrm{C}_{6}$ carbide, and $\mathrm{Cr}$ atoms were partially replaced by Mo atoms. The SAED pattern in Fig. 4c shows a certain orientation relationship between the needle-like $\mathrm{Cr}_{23} \mathrm{C}_{6}$ carbide with $\gamma$ matrix: $(151)_{\mathrm{Cr}_{23} \mathrm{C}_{6}} / /(111)_{\gamma}$, and the electron diffraction zone axis was $[1 \overline{1} 1]$. Figure $4 \mathrm{c}$ shows that there were three favorable orientations for the needle-like $\mathrm{Cr}_{23} \mathrm{C}_{6}$ carbides, and these orientations crossed each other at $120^{\circ}$ in the space. These favorable orientations were further found to be the three close-packed directions of $\gamma$ phase- $\langle 110\rangle$ direction, along which $\mathrm{Cr}_{23} \mathrm{C}_{6}$ carbides needed the minimum energy to precipitate from the $\gamma$ matrix.

Figure 5 shows the SEM images of the DM after PWHT at $950{ }^{\circ} \mathrm{C}$. There were still a lot of granular $\mathrm{Cr}_{23} \mathrm{C}_{6}$ carbides and part of those linked together at the grain boundaries (Fig. 5a, b). Figure 5a shows that the needle-like $\mathrm{Cr}_{23} \mathrm{C}_{6}$ carbides substantially disappeared in the dendrite arms, only a few in the interdendritic regions. The size of needlelike $\mathrm{Cr}_{23} \mathrm{C}_{6}$ in the width and length increased significantly compared with that at $850{ }^{\circ} \mathrm{C}$. The advantageous precipitation orientations of the carbides still crossed a $120^{\circ}$ in the space (Fig. 5c). Moreover, the $\gamma /$ Laves eutectic structure completely disappeared after PWHT at $950{ }^{\circ} \mathrm{C}$.
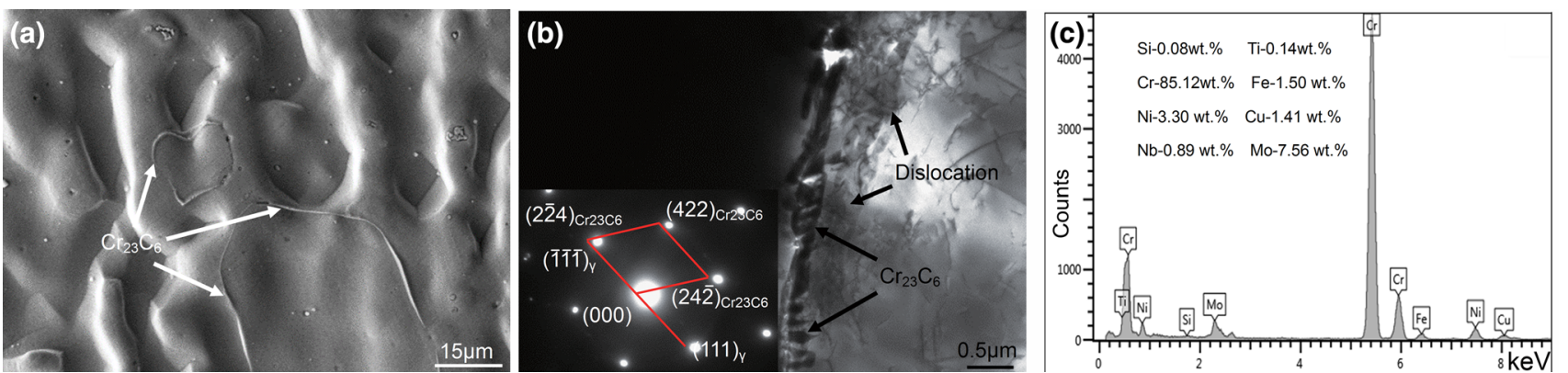

Fig. 2 Analysis of the lamellar-like $\mathrm{Cr}_{23} \mathrm{C}_{6}$ carbides at the grain boundary in the DM after PWHT at $650{ }^{\circ} \mathrm{C}$ : a SEM image, $\mathbf{b}$ TEM image and SAED pattern, $\mathbf{c}$ EDS spectrum 

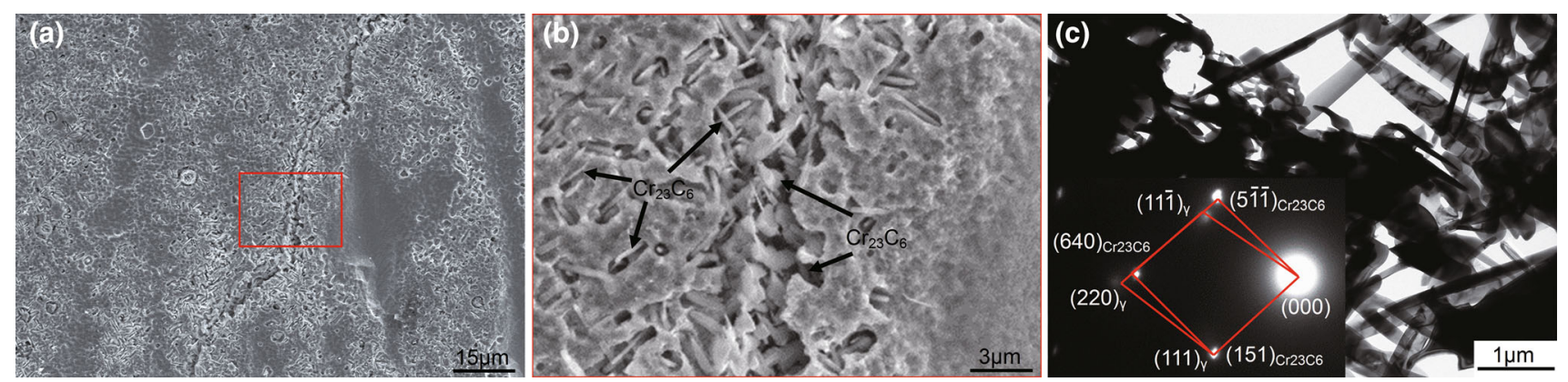

Fig. 4 SEM and TEM analysis of the precipitates in the DM after PWHT at $850{ }^{\circ} \mathrm{C}$ : a granular $\mathrm{Cr}_{23} \mathrm{C}_{6}$ carbides at the grain boundary, $\mathbf{b}$ magnification of the region in the red frame of a, $\mathbf{c}$ TEM image and SAED pattern of the needle-like $\mathrm{Cr}_{23} \mathrm{C}_{6}$ carbides
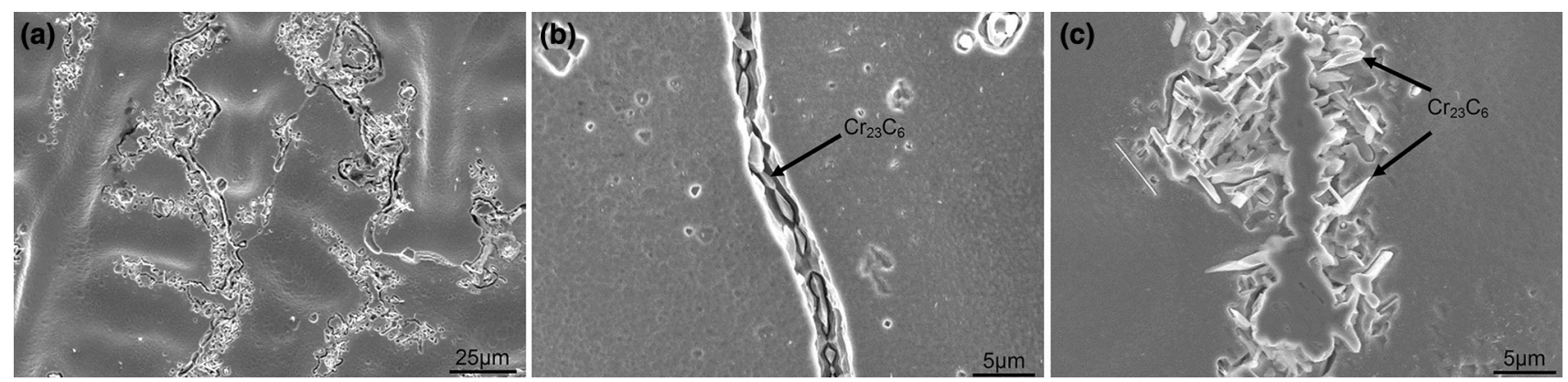

Fig. 5 SEM images of the microstructure in the DM after PWHT at $950{ }^{\circ} \mathrm{C}$ : a precipitates distribution, $\mathbf{b}$ granular $\mathrm{Cr}_{23} \mathrm{C}_{6}$ carbides at the grain boundary, $\mathbf{c}$ needle-like $\mathrm{Cr}_{23} \mathrm{C}_{6}$ carbides in the interdendritic region

\subsection{Electrochemical Corrosion Behavior}

Figure 6 shows the typical Nyquist plots and potentiodynamic polarization curves of the DM in the electrochemical corrosion. The Nyquist plots were all composed of a capacitive loop with one small radius of circular arc at high frequency and a large semicircle that did not end at low frequency for all immersion times. As illustrated in Fig. 6a, the capacitive loop radius of the curve, which was formed in the electrochemical corrosion test for the DM after PWHT at $850{ }^{\circ} \mathrm{C}$, was significantly smaller than that at 650 and $750{ }^{\circ} \mathrm{C}$. The result suggested that the DM after PWHT at $850{ }^{\circ} \mathrm{C}$ had the smaller surface charge transfer resistance, which indicated that the corrosion resistance of the DM after PWHT at $850{ }^{\circ} \mathrm{C}$ was poorer compared with that at 650 and $750{ }^{\circ} \mathrm{C}$. Figure $6 \mathrm{~b}$ shows the potentiodynamic polarization curves. The cathodic branches can be extrapolated back to the corrosion potential $E_{\mathrm{c}}$ to give the corrosion current density $i_{\mathrm{c}}[20,21] . E_{\mathrm{c}}$ and $i_{\mathrm{c}}$ of the DM after PWHT at the three different temperatures were almost equal: $E_{\mathrm{c}}=-0.25 \mathrm{~V}, i_{\mathrm{c}}=4.79 \times 10^{-7} \mathrm{~A} \mathrm{~mm}^{-2}$. Table 1 shows the values of breakdown potential $\left(E_{\mathrm{p}}\right)$ and passive
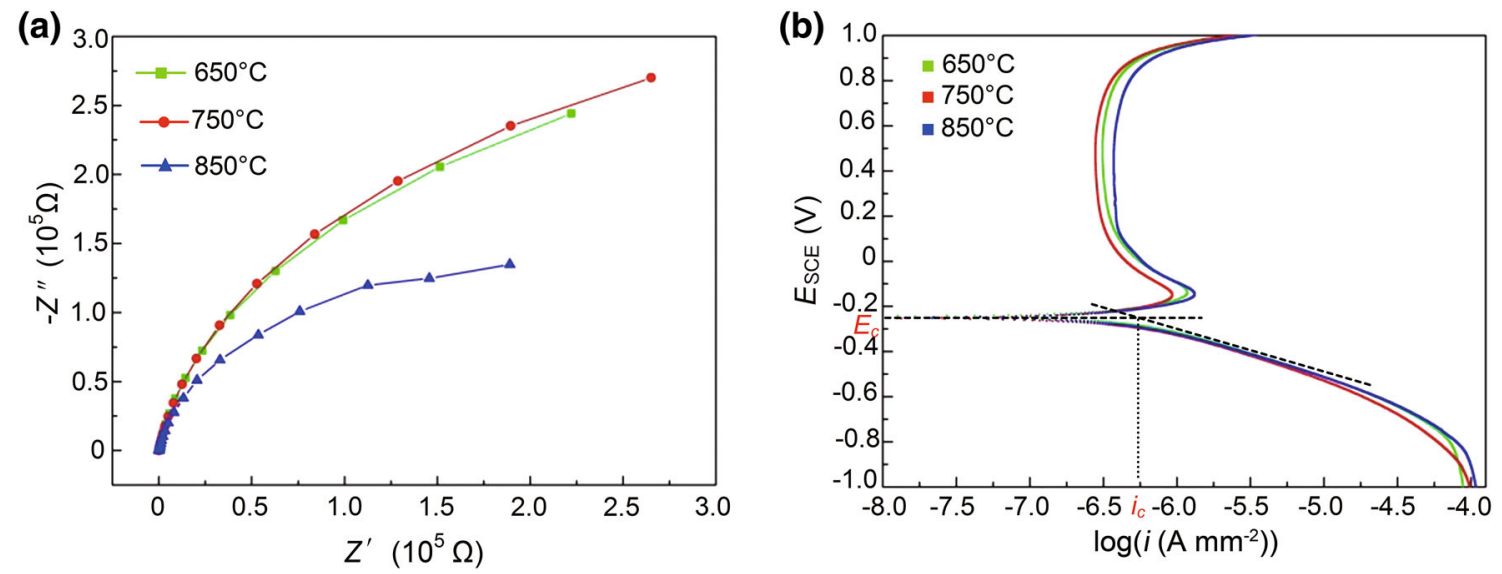

Fig. 6 Electrochemical analysis: a Nyquist plots, b potentiodynamic polarization curves 
Table 1 Values of the breakdown potential $\left(E_{\mathrm{p}}\right)$ and passive current $\left(i_{\mathrm{p}}\right)$ at 650,750 , and $850{ }^{\circ} \mathrm{C}$

\begin{tabular}{lll}
\hline Temperature & $E_{\mathrm{p}}(\mathrm{V})$ & $i_{\mathrm{p}}\left(10^{-7} \mathrm{~A} \mathrm{~mm}^{-2}\right)$ \\
\hline $650{ }^{\circ} \mathrm{C}$ & 0.75 & 2.75 \\
$750{ }^{\circ} \mathrm{C}$ & 0.75 & 3.16 \\
$850^{\circ} \mathrm{C}$ & 0.75 & 3.89 \\
\hline
\end{tabular}

current $\left(i_{\mathrm{p}}\right)$ at 650,750 , and $850{ }^{\circ} \mathrm{C}$. It can be concluded that the $i_{\mathrm{p}}$ was largest at $850{ }^{\circ} \mathrm{C}$ and also indicated that the corrosion resistance of DM after PWHT at $850{ }^{\circ} \mathrm{C}$ was poorer than that at 650 and $750{ }^{\circ} \mathrm{C}$.

\section{Discussion}

Lifshitz-Slyozov-Wagner (LSW) theory describes the kinetics of precipitate coarsening [22, 23], and can be expressed as

$\bar{r}^{3}-\bar{r}_{0}^{3}=k\left(t-t_{0}\right), k=\frac{8 D \gamma S \Omega^{2}}{9 R T}$,

where $r_{0}$ is the average radius of precipitates at the onset of coarsening when $t=t_{0}, r$ is the average radius at time $t, k$ is the rate constant, $D$ is the solute diffusion coefficient, $S$ is the equilibrium concentration of the element in the particles, $\gamma$ is the interfacial energy of needle-like $\mathrm{Cr}_{23} \mathrm{C}_{6}$ carbides and matrix, $\Omega$ is the atomic volume, $R$ is the gas constant, and $T$ is the heat treatment temperature. However, the LSW theory is only limited to the case of spherical particles.

Speich and Oriani had extended the LSW theory to the case of non-spherical particles in the rod shape with hemispherical caps after modifying the rate constant [24, 25]:

$l^{3}-l_{0}^{3}=K\left(t-t_{0}\right), K=\frac{8 D \gamma S \Omega^{2}}{9 R T \beta \ln (2 \beta)}$,

where $l$ is the length of the particles at time $t, l_{0}$ is the average length of the particles when $t=t_{0}, K$ is the rate constant, and $\beta$ is the mean aspect ratio $(\beta=l / 2 r)$ of the major axis $(l)$ to the minor axis $(2 r)$ of the particles.

When the PWHT temperature increased to $850^{\circ} \mathrm{C}$, $\mathrm{Cr}_{23} \mathrm{C}_{6}$ carbides in needle-like morphology could precipitate from $\gamma$ matrix (Fig. 4). To further understand the coarsening characteristic of the needle-like $\mathrm{Cr}_{23} \mathrm{C}_{6}$ carbides, the length $l$ and width $w$ of needle-like $\mathrm{Cr}_{23} \mathrm{C}_{6}$ carbides at $850{ }^{\circ} \mathrm{C}$ for different holding times were
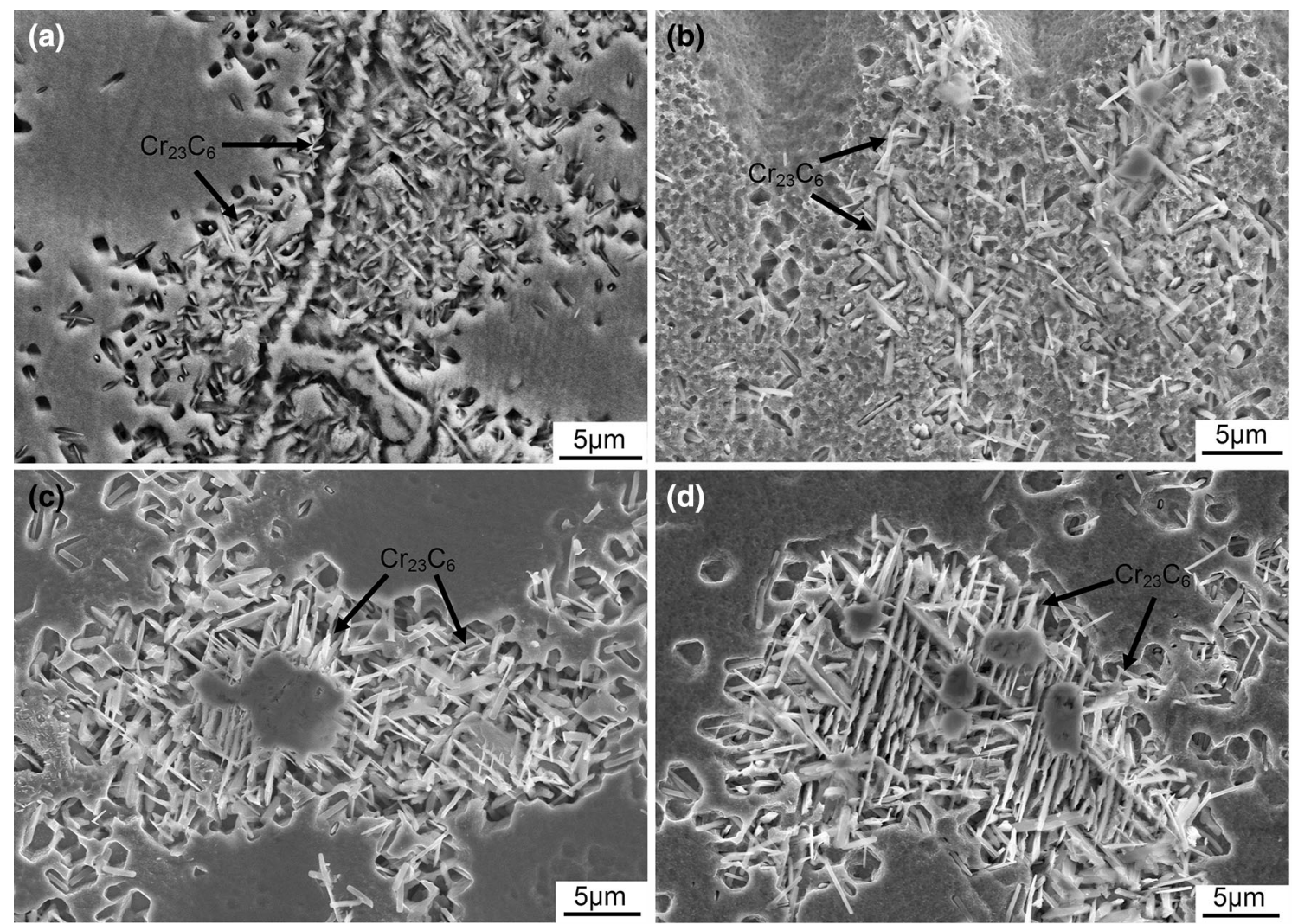

Fig. 7 Morphology of needle-like $\mathrm{Cr}_{23} \mathrm{C}_{6}$ carbides at $850{ }^{\circ} \mathrm{C}$ for different holding times: a $2 \mathrm{~h}, \mathbf{b} 4 \mathrm{~h}, \mathbf{c} 6 \mathrm{~h}, \mathbf{d} 8 \mathrm{~h}$ 
Table 2 Size of the needle-like $\mathrm{Cr}_{23} \mathrm{C}_{6}$ carbides after PWHT at $850{ }^{\circ} \mathrm{C}$ in different holding times

\begin{tabular}{lllll}
\hline$t(\mathrm{~h})$ & $\bar{l}(\mu \mathrm{m})$ & $\vec{l}^{3}\left(\mu \mathrm{m}^{3}\right)$ & $\bar{w}(\mu \mathrm{m})$ & $\bar{w}^{3}\left(10^{-3} \mu \mathrm{m}^{3}\right)$ \\
\hline 2 & 1.66 & 4.59 & 0.19 & 6.44 \\
4 & 2.36 & 13.18 & 0.26 & 17.78 \\
6 & 2.83 & 22.72 & 0.30 & 27.27 \\
8 & 3.25 & 34.25 & 0.34 & 40.35 \\
\hline
\end{tabular}

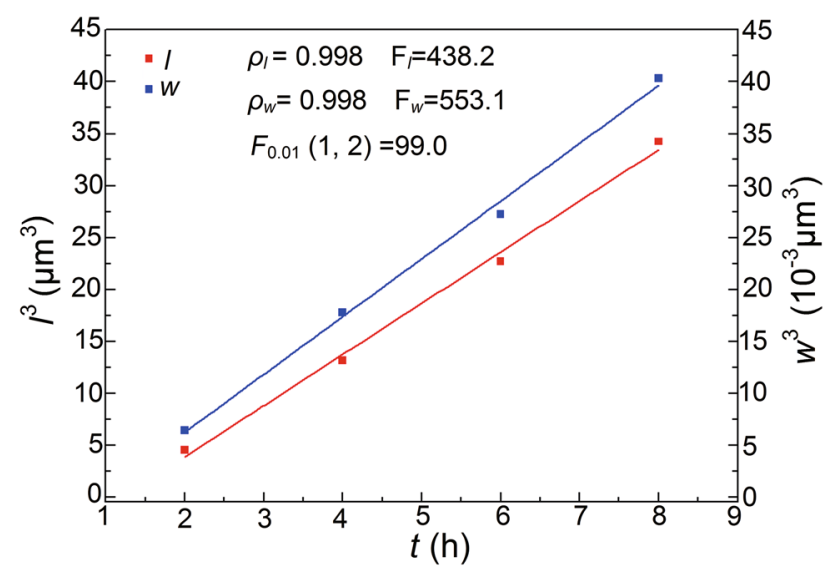

Fig. 8 Linear relationship between the size $\left(\vec{l}^{3}\right.$ and $\left.\bar{w}^{3}\right)$ of needle-like $\mathrm{Cr}_{23} \mathrm{C}_{6}$ carbides and the holding time $t$ at $850{ }^{\circ} \mathrm{C}$ in the DM ( $\rho$ was the correlation coefficient, and through the analysis of variance, the $F$ value can be obtained)

investigated. Figure 7 shows that not only did the number of needle-like $\mathrm{Cr}_{23} \mathrm{C}_{6}$ carbides increase, but also the size both in length and width became larger obviously with prolonging the holding time. The average length $\bar{l}$ and width $\bar{w}$ of the needle-like $\mathrm{Cr}_{23} \mathrm{C}_{6}$ carbides in different holding times are listed in Table 2.

According to Table 2, the linear regression equation about $t$ and the size $\left(\vec{l}^{3}, \bar{w}^{3}\right)$ was fitted by the least square method:

$\vec{l}^{3}-5.95=4.93(t-2)$,

$\bar{w}^{3}-4.85 \times 10^{-3}=5.56 \times 10^{-3}(t-2)$,

Figure 8 shows that there was a good linear relationship between $t$ and the size $\left(\vec{l}^{3}\right.$ and $\left.\bar{w}^{3}\right)$, which implied that the growth of needle-like $\mathrm{Cr}_{23} \mathrm{C}_{6}$ carbides well met the LSW aging theory. Furthermore, Eqs. (3) and (4) revealed that the growth speed of needle-like $\mathrm{Cr}_{23} \mathrm{C}_{6}$ carbides was $K_{1}=$ $4.93 \mu \mathrm{m}^{3} / \mathrm{h}$ and $K_{\mathrm{w}}=5.56 \times 10^{-3} \mu \mathrm{m}^{3} / \mathrm{h}$ in DM under PWHT at $850{ }^{\circ} \mathrm{C}$ for $2-8 \mathrm{~h}$. Obviously, the growth speed in length of the needle-like $\mathrm{Cr}_{23} \mathrm{C}_{6}$ carbides was much faster than that in width.

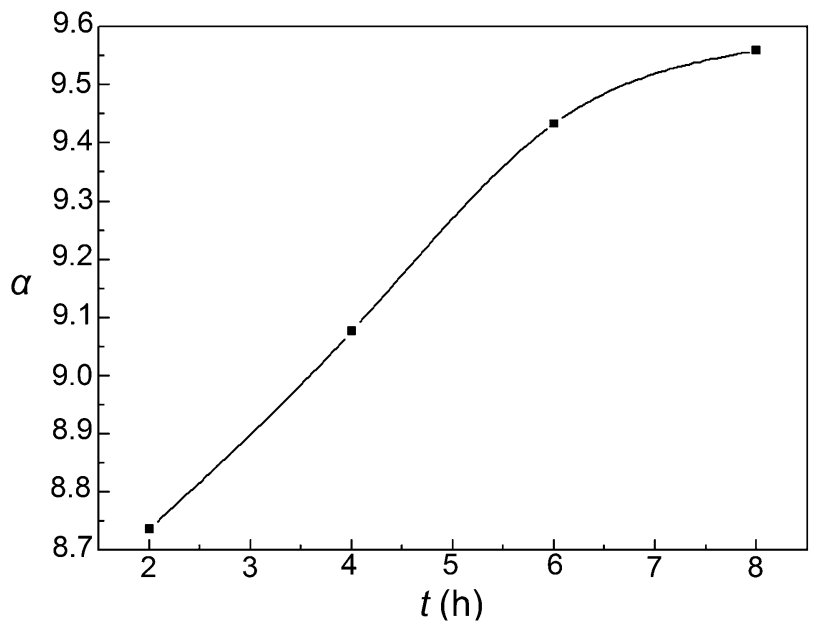

Fig. 9 Relationship between $\alpha(\alpha=\bar{l} / \bar{w})$ and the holding time $t$

Figure 9 shows the law that the ratio $\alpha$ of $\bar{l}$ to $\bar{w}$ varied with the holding time. When the holding time was prolonged, $\alpha$ value increased, but the increase rate decreased. When the needle-like $\mathrm{Cr}_{23} \mathrm{C}_{6}$ carbide precipitated coherently with the $\gamma$ matrix, the final shape of the needle-like $\mathrm{Cr}_{23} \mathrm{C}_{6}$ carbide not only depended on the minimum interfacial energy criterion, but also needed to meet the minimum elastic energy criterion [26, 27]:

$\alpha=\frac{\gamma_{1}}{\gamma_{\mathrm{w}}}+\frac{\pi A t}{12 \gamma_{\mathrm{w}}}$

where $\gamma_{1}$ and $\gamma_{w}$ are the interfacial energy between the needle-like $\mathrm{Cr}_{23} \mathrm{C}_{6}$ carbide and the $\gamma$ matrix in length and width directions, respectively, and $A$ is the parameter that related the mismatch degree. Equation (5) shows that the value of $\alpha$ tends to the ratio of $\gamma_{1}$ to $\gamma_{\mathrm{w}}$ when the size of needle-like $\mathrm{Cr}_{23} \mathrm{C}_{6}$ carbide is much small, that is, $A$ is close to zero. The elastic strain energy increased with the needlelike $\mathrm{Cr}_{23} \mathrm{C}_{6}$ carbide growth. When the needle-like $\mathrm{Cr}_{23} \mathrm{C}_{6}$ carbides grew to a certain extent, the value of $\alpha$ mainly depended on the elastic strain energy of the carbides, resulting in the constant increase in $\alpha$ value. The increase rate of $\alpha$ reduced when the needle-like $\mathrm{Cr}_{23} \mathrm{C}_{6}$ carbide and $\gamma$ matrix lost the coherent relationship. The above analysis was consistent with the changing rule (Fig. 9) that the measured $\alpha$ value rapidly increased in the initial stage and then flattened with the increase in holding time.

To further understand the corrosion resistance of the alloy at different PWHT temperatures, the DM was analyzed by SEM after the electrochemical corrosion, as shown in Fig. 10. It can be observed that almost no corrosion occurred on the DM after PWHT at 650 and $750{ }^{\circ} \mathrm{C}$, but the DM after PWHT at $850{ }^{\circ} \mathrm{C}$ suffered severe corrosion, especially around the needled-like $\mathrm{Cr}_{23} \mathrm{C}_{6}$ carbides. As the needle-like $\mathrm{Cr}_{23} \mathrm{C}_{6}$ carbides precipitation occurred, 

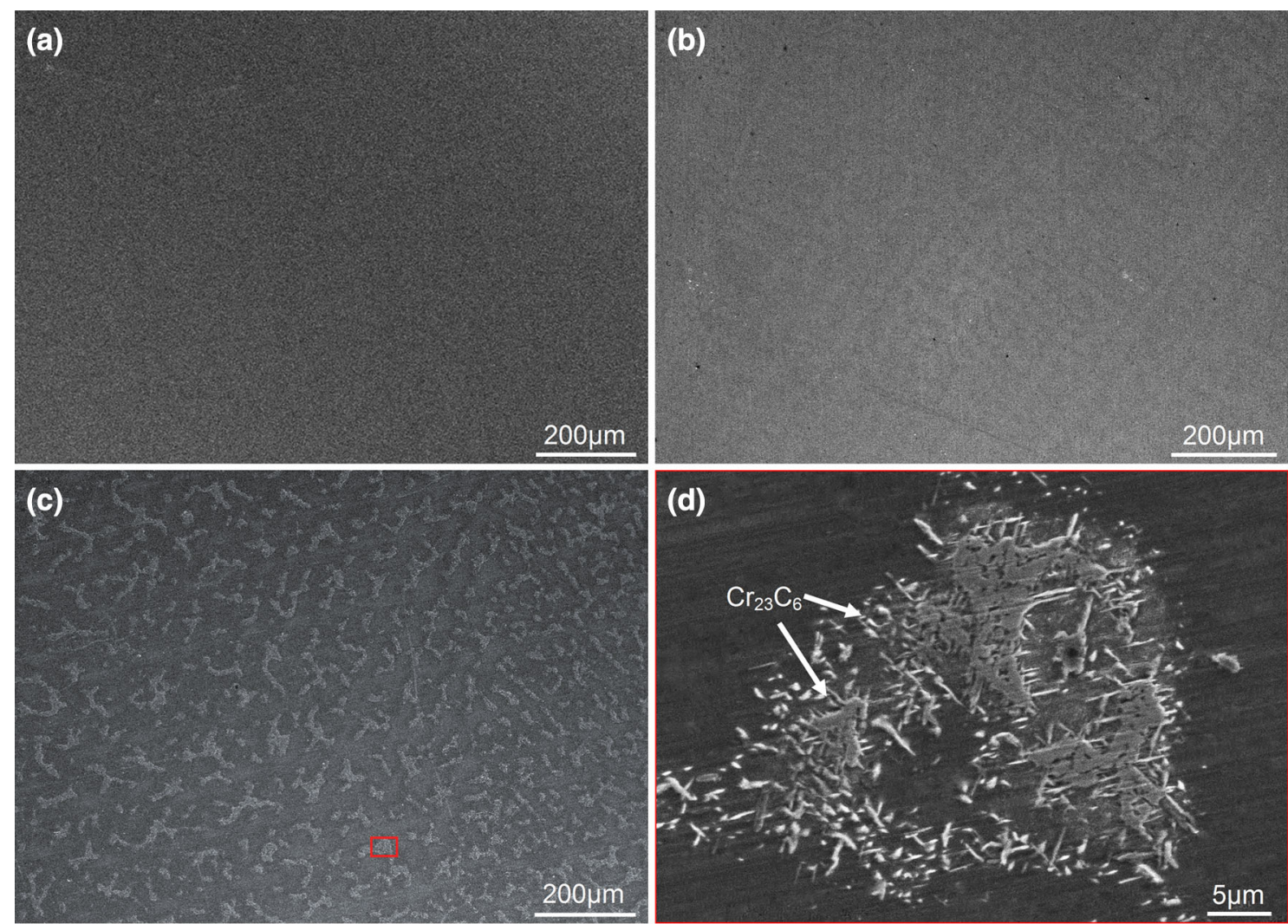

Fig. 10 SEM images of the DM with PWHT at various temperatures for $4 \mathrm{~h}$ after the electrochemical corrosion: a $650{ }^{\circ} \mathrm{C}, \mathbf{b} 750{ }^{\circ} \mathrm{C}, \mathbf{c} 850{ }^{\circ} \mathrm{C}$, d magnification of the region in the red frame of $\mathbf{c}$

$\mathrm{Cr}$ atoms would be consumed from the $\gamma$ matrix nearby needle-like $\mathrm{Cr}_{23} \mathrm{C}_{6}$ carbides. The Cr-depleted zone would be formed around the needle-like $\mathrm{Cr}_{23} \mathrm{C}_{6}$ carbides. The corrosion resistance surrounding the needled-like $\mathrm{Cr}_{23} \mathrm{C}_{6}$ carbides would decrease owing to the $\mathrm{Cr}$ depletion at that local region [15].

\section{Conclusions}

1. The morphology of the $\mathrm{Cr}_{23} \mathrm{C}_{6}$ carbides at the grain boundaries transformed from the continuous lamellarlike to the semi-continuous rod-like and then to the discontinuous granular with the increase in PWHT temperature.

2. The needle-like $\mathrm{Cr}_{23} \mathrm{C}_{6}$ carbides precipitated from $\gamma$ matrix after PWHT at $850{ }^{\circ} \mathrm{C}$. The growth of the carbide in length and width coincided with the LSW law with the extension of the holding time at $850{ }^{\circ} \mathrm{C}$.

3. According to the result of the electrochemical experiment, the corrosion resistance of $\mathrm{DM}$ was poorer after PWHT at $850{ }^{\circ} \mathrm{C}$ than that at 650 and $750{ }^{\circ} \mathrm{C}$. Due to the needle-like $\mathrm{Cr}_{23} \mathrm{C}_{6}$ carbides precipitation after PWHT at $850{ }^{\circ} \mathrm{C}$, the $\mathrm{Cr}$-depleted regions around the carbides formed. The corrosion resistance of DM decreased significantly in those regions.

\section{References}

[1] S.L. McCracken, B.T. Alexandrov, J.C. Lippold, J.W. Sowards, A.T. Hope, in: Proceedings of the Asme Pressure Vessels and Piping Conference, Hot Cracking Study of High Chromium Nickel-Based Weld Filler Metal 52MSS (ERNiCrFe-13) for Nuclear Applications, Bellevue, Washington, USA (2010)

[2] M. Kanzaki, Y. Masaki, T. Kudo, Corros. Sci. 71, 1027 (2015)

[3] S. Guan, C.Y. Cui, Acta Metall. Sin. (Engl. Lett.) 28, 1083 (2015)

[4] K. Ahluwalia, C. King, Review of Stress Corrosion Cracking of Alloy 182 and 82 in PWR Primary Water Service (MRP-220) (Electric Power Research Institute, Palo Alto, 2007)

[5] P.L. Andresen, M. Morram, Materials Reliability Program: Resistance of Alloy 690/52/152 to SCC Crack Growth in Simulated PWR Primary Water (MRP-196) (Electric Power Research Institute, Palo Alto, 2006)

[6] F.G. Hodge, JOM 58, 28 (2006)

[7] J.C. Lippold, S.D. Kiser, J.N. DuPont, Welding Metallurgy and Weldability of Nickel-Base Alloys, 1st edn. (Wiley, New Jersey, 2009)

[8] Y. Xie, Y. Wu, J. Burns, J. Zhang, Mater. Charact. 112, 87 (2016)

[9] A.J. Ramirez, J.C. Lippold, Mater. Sci. Eng., A 380, 259 (2004) 
[10] A.J. Ramirez, J.C. Lippold, Mater. Sci. Eng., A 380, 245 (2004)

[11] W. Sun, X.Z. Qin, J.T. Guo, L.H. Lou, L.Z. Zhou, Mater. Des. 69, 81 (2015)

[12] K. Zhao, L.H. Lou, Y.H. Ma, Z.Q. Hu, Mater. Sci. Eng., A 476, 372 (2008)

[13] H.T. Lee, J.L. Wu, Corros. Sci. 52, 1545 (2010)

[14] T.H. Chen, J.R. Yang, Mater. Sci. Eng., A 311, 41 (2001)

[15] T.M. Angeliu, G.S. Was, Metall. Mater. Trans. A 21, 2097 (1990)

[16] S.L. Yun, J.K. Dong, S.S. Hwang, P.K. Hong, S.W. Kim, Mater. Charact. 96, 28 (2014)

[17] D. Wang, J. Zhang, L.H. Lou, Mater. Charact. 60, 1517 (2009)

[18] H.U. Hong, B.S. Rho, S.W. Nam, Mater. Sci. Eng., A 318, 285 (2001)
[19] X.J. Di, B. Chen, Sci. Technol. Weld. Joining 20, 325 (2015)

[20] T. Chen, H. John, J. Xu, Q.H. Lud, J. Hawka, X.B. Liu, Corros. Sci. 77, 230 (2013)

[21] E. Mccafferty, Corros. Sci. 47, 3202 (2005)

[22] D. Fan, L.Q. Chen, S.P. Chen, P.W. Voorhees, Comput. Mater. Sci. 9, 329 (1998)

[23] S. Balachandran, A. Kashiwar, A. Choudhury, D. Banerjee, R. Shi, Y.Z. Wang, Acta Mater. 106, 374 (2016)

[24] C. Watanabe, T. Kondo, R. Monzen, Metall. Mater. Trans. A 35, 3003 (2004)

[25] R. Monzen, T. Tada, T. Seo, K. Higashimine, Mater. Lett. 58, 2007 (2004)

[26] J.W. Cahn, Acta Metall. 14, 83 (1966)

[27] R.A. Oriani, Acta Metall. 12, 1399 (1964) 